\title{
Does AP CS Principles Broaden Participation in Computing?
}

\author{
An Analysis of APCSA and APCSP Participants
}

\author{
Linda J. Sax \\ Graduate School of Education \& \\ Information Studies \\ UCLA \\ Los Angeles, CA USA \\ lsax@ucla.edu \\ Max Skorodinsky \\ Department of Education Studies \\ University of Oregon \\ Eugene, OR USA \\ makseem@uoregon.edu
}

\author{
Kaitlin N.S. Newhouse \\ Graduate School of Education \& \\ Information Studies \\ UCLA \\ Los Angeles, CA USA \\ k.newhouse@ucla.edu
}

\author{
Tomoko M. Nakajima \\ Graduate School of Education \& \\ Information Studies \\ UCLA \\ Los Angeles, CA USA \\ tnak493@gmail.com
}

\author{
Joanna Goode \\ Department of Education Studies \\ University of Oregon \\ Eugene, OR USA \\ goodej@uoregon.edu
}

\begin{abstract}
A major attempt to broaden participation in computer science has centered on the design and development of a new high school Advanced Placement (AP) course, AP Computer Science Principles (CSP). This course was created to intentionally engage a wider and more diverse group of students in learning about computing than those who had historically enrolled in programming-focused AP Computer Science "A" (CSA). After several years in the pilot phase, the course was officially offered by the College Board in 2016-17. This paper uses nationwide Freshman Survey data to examine the demographics and characteristics of students who took either CSA, the new CSP course, or both courses by the time they entered college in Fall 2017. Using crosstabs, z-tests, and one-way ANOVA, this study uncovered the similarities and differences between students who had participated in one or both of these courses. Our findings suggest that while students who took only CSP were more diverse than those who took only CSA, they exhibited less computing confidence and less interest in computing majors and tech careers. This study suggests that while CSP may be recruiting more females and racially diverse students into the course, this course alone may not serve as a direct pipeline into computing majors and careers.
\end{abstract}

Permission to make digital or hard copies of all or part of this work for personal or classroom use is granted without fee provided that copies are not made or distributed for profit or commercial advantage and that copies bear this notice and the full citation on the first page. Copyrights for components of this work owned by others than the author(s) must be honored. Abstracting with credit is permitted. To copy otherwise, or republish, to post on servers or to redistribute to lists, requires prior specific permission and/or a fee. Request permissions from Permissions@acm.org.

SIGCSE '20, March 11-14, 2020, Portland, OR, USA

(c) 2020 Copyright is held by the owner/author(s). Publication rights licensed to ACM.

ACM 978-1-4503-6793-6/20/03...\$15.00

https://doi.org/10.1145/3328778.3366826

\section{KEYWORDS}

AP Computer Science A Course/Exam, AP Computer Science Principles Course/Exam, Gender and Diversity

\author{
Michelle Sendowski \\ Graduate School of Education \& \\ Information Studies \\ UCLA \\ Los Angeles, CA USA \\ michelle.sendowski@gmail.com
}

\section{ACM Reference format:}

Linda J. Sax, Kaitlin N.S. Newhouse, Joanna Goode, Max Skorodinsky, Tomoko M. Nakajima, and Michelle Sendowski. 2020. Does AP CS Principles Broaden Participation in Computing? An Analysis of APCSA and APCSP Participants. In Proceedings of ACM Special Interest Group on Computer Science Education conference (SIGCSE '20). ACM, Portland, OR, USA. ACM. New York, NY. USA. 7 pages. https://doi.org/10.1145/3328778.3366826

\section{Broadening Participation in Computing}

The field of K-12 computer science education has been plagued by low rates of participation among girls and students of color, more so than any other subject in the school curriculum. Research has shown that both structural constraints-such as the lack of available classes and qualified teachers-as well as biased belief systems about who belongs in computer science limit certain students' exposure to learning opportunities in computing [12]. Further, a focus on programming as the skill primarily valued in computing can overshadow the creative and collaborative aspects of the discipline and discourage broad groups of students from pursuing computer science for future study or careers.

In an effort to disrupt gender and racial inequities in participation in computer science, the National Science Foundation (NSF) and the College Board collaborated to design a new advanced course for high school students - Advanced Placement CS Principles (CSP) [6, 11]. Though there has been significant investment and support to offer the course throughout the country, less is known about the impact of this course on broadening participation in computer science majors and careers. Howard and Havard's [10] recent comparison of AP 
CSA and AP CSP exam scores found that, in 2017 and 2018, larger proportions of women, Black/African American, and Latinx students took the CSP exam. Other work [7] has also compared students in CSA and CSP courses and found few differences by course type in students' computing self-efficacy, sense of belonging, or their interest in pursuing computing in the future. This study builds upon this extant research and aims to reveal further insights into which students take the new APCSP course relative to those who take APCSA. Also, unlike prior work, we investigate how participation in one or both of these courses relates to intended participation in computing in college and beyond. Specifically, we sought to answer the following research questions:

1. What are the demographic and academic characteristics of first-year college students who had taken AP Computer Science A, AP Computer Science Principles, or both courses? Are there significant differences in these characteristics across the three groups?

2. To what extent do first-year college students who had taken one or both Advanced Placement Computer Science courses indicate engagement and interest in computing? Are there significant differences in computing engagement or interest among students who had taken AP Computer Science A, AP Computer Science Principles, and both courses?

3. What are the major and career aspirations of first-year students who had taken Advanced Placement Computer Science A, Advanced Placement Computer Science Principles, or both courses? Are there significant differences in major and career aspirations across the three groups?

\section{Comparing the AP CS Courses}

\subsection{AP Computer Science A Course}

The College Board currently offers 38 AP courses across a variety of subjects, which enable students to earn college credit for courses taken during high school [5]. The CSA course, first introduced in 1984, focuses on object-oriented programming and data structures, with Java as the primary emphasis and designated programming language of the course [2]. Until the 2016-17 school year, CSA was the only AP computing course available, "intended to serve both as an introductory course for computer science majors and as a course for people who will major in other disciplines and want to be informed citizens in today's technological society" [2]. Similar to other AP courses, the exam for this course is at the end of the year and includes a set of multiple-choice questions and four free-response items. This computer science course continues to be broadly offered by the College Board, and publicly available APCSA test-taker data is published annually.

Though the CSA course has been offered for decades, until recently the number of test-takers has historically been relatively low compared to other AP mathematics and science courses, with only 15,000 students taking the test a decade ago [1]. Since then, participation in the CSA exam has surged with a student participation growth rate of $9-26 \%$ each year until the introduction of CSP in 2016-17, which slightly reduced the growth in CSA [10]. As shown in Table 1, in 2017, 60,519 students completed the AP CSA exam [4], with 5,040 schools offering the exam. Still, of all the AP course offerings, this course has historically suffered from the lowest rates of participation for girls and students of color. Girls represented only $23.6 \%$ of exam-takers and African Americans, Latinos, Pacific Islanders, and Native Americans made up a combined $16 \%$ of participants. Further, exam scores for historically underserved students are much lower than those of their peers. For instance, Latina and Black girls are only half as likely as their White and Asian classmates to be awarded scores of 3 or higher on the CSA exam [8].

Table 1: Comparison of APCSA vs. APCSP Exam-Takers, As Reported by the College Board (2017)

\begin{tabular}{|c|c|c|}
\hline & \multicolumn{2}{|c|}{ Percent Among } \\
\hline & $\begin{array}{c}\text { APCSA } \\
\mathrm{n}=60,519\end{array}$ & $\begin{array}{c}\text { APCSP } \\
\mathrm{n}=44,330\end{array}$ \\
\hline \multicolumn{3}{|l|}{ Sex } \\
\hline Male & 76.4 & 70.0 \\
\hline Female & 23.6 & 30.0 \\
\hline \multicolumn{3}{|l|}{ Race/Ethnicity } \\
\hline African American/Black & 3.8 & 7.2 \\
\hline American Indian & 0.2 & 0.2 \\
\hline Asian American/Asian & 30.9 & 23.4 \\
\hline Hispanic/Latino/Chicano & 11.8 & 20.2 \\
\hline Pacific Islander & 0.1 & 0.2 \\
\hline White/Caucasian & 48.6 & 48.7 \\
\hline Other & 0.0 & 0.0 \\
\hline Two or More Races & 4.6 & 4.7 \\
\hline \multicolumn{3}{|l|}{ Grade Level } \\
\hline Students in $9^{\text {th }}$ & 2.1 & 8.2 \\
\hline Students in $10^{\text {th }}$ & 18.3 & 23.6 \\
\hline Students in $11^{\text {th }}$ & 35.4 & 30.1 \\
\hline Students in $12^{\text {th }}$ & 42.1 & 35.2 \\
\hline Public School Students & 85.5 & 88.1 \\
\hline
\end{tabular}

Source. College Board Advanced Placement National Summary 2017.

\subsection{AP Computer Science Principles Course}

In a concerted effort to broaden participation in computing, the College Board and the National Science Foundation began in 2008 to design, develop, and implement AP Computer Science Principles, a more accessible, college-level computer science course $[6,11]$. The APCSP course focuses on seven core computing concepts (creativity, abstraction, data and information, algorithms, programming, the Internet, and global impact) and six computational practices (connecting computing, creating computational artifacts, abstracting, analyzing problems and artifacts, communicating, and collaborating) [3]. Given the focus on a breadth of foundational ideas in computing rather than programming language particulars, the course and exam are programming-language agnostic, allowing for instructors to select the programming language they deem most appropriate for student success in their own classrooms [6]. Also unique to CSP are two through-course, teacher-supervised performance 
assessments (an Explore: Impact of Computing Innovations task and a Create: Application to Ideas task) that make up $40 \%$ of students' final AP score [3]. These tasks, along with the end-ofcourse multiple-choice exam common among AP courses, are designed to assess students' content knowledge throughout the year-long class.

After eight years of development and piloting, CSP boasted the largest launch of any AP course in College Board history [11], with over 44,000 students taking the exam in 2017 (at 2,625 schools) and 70,000 students taking the exam in 2018 (at 4,022 schools) [3, 4]. The inaugural group of CSP exam-takers in 2017 was comprised of $30 \%$ girls and $28 \%$ historically underserved students of color [4]. While CSP test-takers were more diverse than CSA by comparison, CSP's population still fell short of gender and racial parity with the national high school student population [4].

\section{Methods}

\subsection{Data Source and Sample}

This study used data from the 2017 Freshman Survey, which was administered to students attending 168 four-year colleges and universities participating in the Cooperative Institutional Research Program (CIRP) Freshman Survey conducted by UCLA's Higher Education Research Institute (HERI) [15]. The Freshman Survey (TFS) is distributed to students at participating institutions at the start of their first year of college, and asks questions on a wide variety of topics, including students' demographic characteristics, academic performance and participation in high school activities, self-ratings, and their goals and aspirations while in college and beyond. These data are different from data on AP students reported by the College Board since TFS data reflect AP course takers (not only exam takers) and include a broader range of variables.

Our analyses drew from 120,357 first-time full-time college students who entered their first semester at a four-year college or university in the fall of 2017 [15]. We restricted the sample to 8,844 students who had taken an AP CS course in high school and also indicated an aspiration to earn at least a bachelor's degree. This resulted in 6,098 students who stated that they had taken CSA, 1,851 students who took CSP, and 895 students who had taken both courses. Because the TFS does not ask when students took these courses, we do not know which year(s) students took which AP CS courses. However, we note that CSP officially rolled out in 2016-17 (the year prior to these students' college entry) and was in a more limited pilot phase in prior years.

\subsection{Data Analysis}

To examine differences among students who took AP CS courses, we compared students who took CSA, CSP, and both courses to one another across a variety of categories including their demographic characteristics, academic achievements, their perceptions of their own computing skills, intended major, and career aspirations. We ran crosstabulations and performed ztests on proportions with the Bonferroni correction to determine statistically significant differences in proportions of students in each group. We also performed one-way analysis of variance (ANOVA) testing with post-hoc tests to examine significant differences in mean standardized test scores across these three AP course-taking groups.

\section{Results}

This section reports on the comparison of students across the three groups (students who took CSA, CSP, and both courses). While all of the significant differences are noted in the tables, here we summarize some of the most striking differences among the groups. Note that when describing results for students taking APCSA or APCSP, we are referring to students who took only that course; students who took both courses are only reflected in the third "Both" category

\subsection{Demographic Characteristics}

In addressing our first research question, we began with a focus on the demographic characteristics of students who took one or both AP CS courses (see Table 2).

Table 2: Demographic Characteristics: Differences Across AP CS Course-Takers (2017)

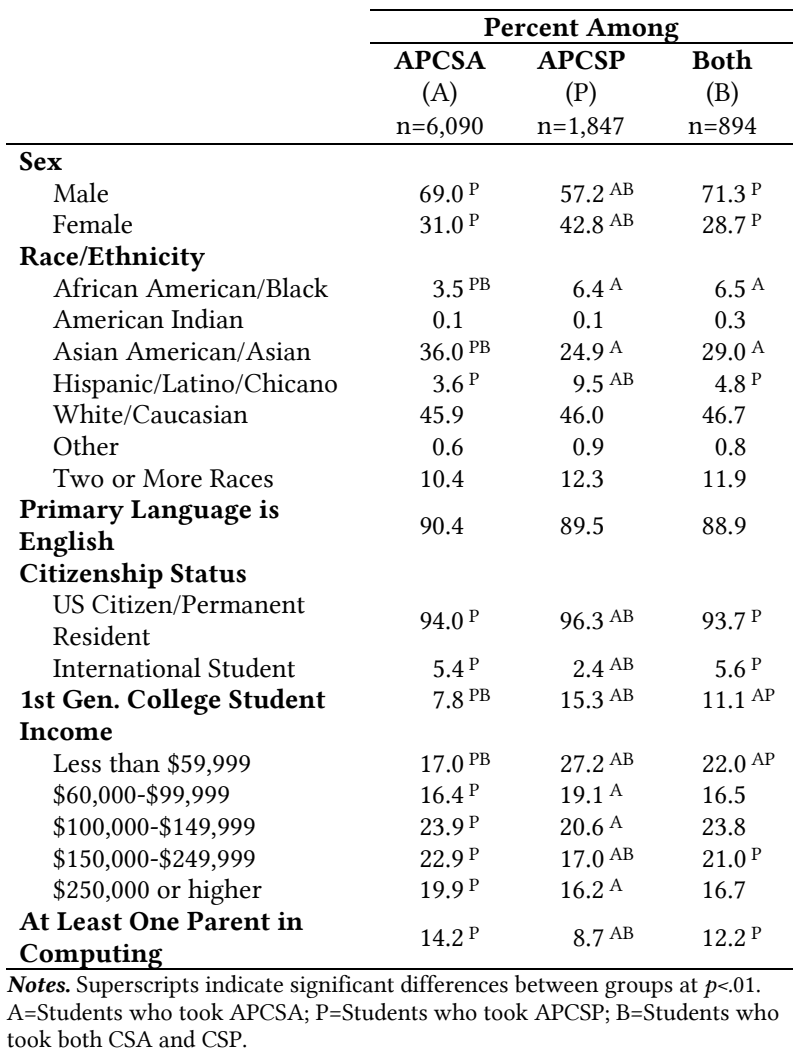

Findings show that, in general, students who took only CSP were more representative of groups historically underrepresented in computing. For example, although females were the minority of CS course-takers across all three groups, 
they were best represented among CSP students (42.8\%) relative to CSA $(31 \%)$ or both courses $(28.7 \%)$. We also observed significant differences when comparing students' racial/ethnic identification across the three sub-groups. African American and Black students were better represented in CSP (6.4\%) than in CSA (3.5\%), though they also comprised $6.5 \%$ of those taking both courses. CSP was also more popular among Latinx students, who were better represented among those taking only CSP (9.5\%) than among those taking only CSA (3.6\%) or both courses (4.8\%). Asian students, on the other hand, were significantly better represented among those taking only CSA (36\%) versus only CSP $(24.9 \%)$ or both courses (29\%). Finally, White students were the majority of AP CS course-takers, representing more than $45 \%$ of students in each course-taking category, but their representation did not vary across groups.

Our results also showed that both first-generation college students (who indicated that neither parent had attended any college) and lower-income students were better represented among CSP course-takers than they were in the other two groups. In fact, the proportion of students who are firstgeneration is twice as high among CSP students versus those taking CSA (15.3\% vs. $7.8 \%$ ). Further, while the sample overall skewed fairly wealthy, students in the lowest quintile of selfreported annual family income were significantly better represented among those taking CSP. In fact, $27.2 \%$ of students who took only CSP indicated their family earned less than $\$ 59,999$ last year (relative to $17.0 \%$ among CSA-takers and $22.0 \%$ among those taking both courses). In general, as family incomes increased, students were more likely to have taken only CSA or both courses ${ }^{1}$. Some differences in family income among AP CS course-takers may be explained by their parents' professions: significantly more students who took only CSA $(14.2 \%)$ or both courses $(12.2 \%)$ indicated having at least one parent in a computing or tech career compared to students who took only $\operatorname{CSP}(8.7 \%)$.

\subsection{Academic Achievement}

Overall, the students in our sample indicated high levels of academic achievement prior to entering college (see Table 3). In fact, among students who took only CSA, more than half (50.9\%) indicated that their high school grades averaged an A+ or A, while $42.1 \%$ of those who took only CSP and $43 \%$ of students who took both courses indicated near-perfect high

\footnotetext{
${ }^{1}$ To determine if these findings were driven by the affluence of high schools that offered these courses, we matched students' self-reported high school to publicly available school-level data from the National Center for Education Statistics $[13,14]$ to run post-hoc analyses on the type of high schools students in each group attended (e.g. public, private, home schooled, eligible for Title I funding). We found few significant differences that would explain the racial and gender differences in AP CS course participation; however, students who took only CSP were significantly more likely $(44 \%)$ to have attended a Title I eligible school than students who took only CSA (35.5\%) or both courses $(34.6 \%)$. Title I provides supplemental funding for schools with large concentrations of students in poverty.
}

School grades. Taking multiple AP courses was also common among all three groups, and more than half of the students in each course category did so. Among the other AP courses these students took, AP Calculus was the most popular among students in each category, however significantly more students who took only CSA (82.5\%) reported taking AP Calculus, compared to $63.8 \%$ of students who took only CSP, and the $74.7 \%$ of students who took both AP CS courses.

Table 3. Academic Achievement: Differences Across AP CS Course-Takers (2017)

\begin{tabular}{|c|c|c|c|}
\hline & \multicolumn{3}{|c|}{ Percent Among } \\
\hline & $\begin{array}{c}\text { APCSA } \\
\text { (A) }\end{array}$ & $\begin{array}{c}\text { APCSP } \\
\text { (P) }\end{array}$ & $\begin{array}{l}\text { Both } \\
\text { (B) }\end{array}$ \\
\hline & $\mathrm{n}=6,077$ & $\mathrm{n}=1,844$ & $\mathrm{n}=892$ \\
\hline \multicolumn{4}{|c|}{ Average High School Grades } \\
\hline $\mathrm{A}+$ or $\mathrm{A}$ & $50.9^{\mathrm{PB}}$ & $42.1^{\mathrm{A}}$ & $43.0^{\mathrm{A}}$ \\
\hline A- & 30.0 & 30.2 & 27.8 \\
\hline $\mathrm{B}+$ & $11.1^{\mathrm{PB}}$ & $15.9^{\mathrm{A}}$ & $15.4^{\mathrm{A}}$ \\
\hline B & $6.3^{\mathrm{PB}}$ & $8.7^{\mathrm{A}}$ & $9.6^{\mathrm{A}}$ \\
\hline B- or Below & $1.7 \mathrm{~PB}$ & $3.1^{\mathrm{A}}$ & $4.1^{\mathrm{A}}$ \\
\hline 5+ AP Courses Taken & $75.5^{\mathrm{PB}}$ & $63.3 \mathrm{~A}$ & $65.2^{\mathrm{A}}$ \\
\hline \multicolumn{4}{|c|}{ AP STEM Course Enrollment } \\
\hline Probability/Statistics & $43.0^{\mathrm{P}}$ & $35.0 \mathrm{AB}$ & $46.3^{\mathrm{P}}$ \\
\hline Calculus & $82.5^{\mathrm{PB}}$ & $63.8^{\mathrm{AB}}$ & 74.7 AP \\
\hline Biology & 36.8 & 36.0 & 37.8 \\
\hline Chemistry & $44.5^{\mathrm{P}}$ & $33.2 \mathrm{AB}$ & $41.0^{\mathrm{P}}$ \\
\hline Physics & $63.8^{\mathrm{P}}$ & $41.5 \mathrm{AB}$ & $60.4^{\mathrm{P}}$ \\
\hline \multirow[t]{3}{*}{ Environmental Science } & 17.7 PB & $21.6^{\mathrm{A}}$ & $25.4^{\mathrm{A}}$ \\
\hline & \multicolumn{3}{|c|}{ Mean Scores Among } \\
\hline & $\begin{array}{l}\text { APCSA } \\
\text { (A) }\end{array}$ & $\begin{array}{c}\text { APCSP } \\
\text { (P) }\end{array}$ & $\begin{array}{c}\text { Both } \\
\text { (B) }\end{array}$ \\
\hline \multicolumn{4}{|l|}{ Standardized Test Scores 1} \\
\hline ACT Composite & $31.2^{\mathrm{PB}}$ & $28.6 \mathrm{AB}$ & $29.8 \mathrm{AP}$ \\
\hline SAT Math & 717.7 РВ & $658.0 \mathrm{AB}$ & $686.1 \mathrm{AP}$ \\
\hline SAT Verbal & $683.1 \mathrm{~PB}$ & $638.2^{\mathrm{AB}}$ & $660.0 \mathrm{AP}$ \\
\hline
\end{tabular}

${ }^{1}$ Proportions of missing data were higher on these variables (38\%-44\% missing). We reported ACT mean scores from 3,782 APCSA students, 1,075 APCSP students, and 515 students who took both courses. Reported SAT Math mean scores are based on 3,801 APCSA students, 1,072 APCSP students, and 542 students who took both courses. Reported mean SAT verbal scores are based on 3,744 APCSA students, 1,058 APCSP students, and 528 students who took both courses.

\subsection{Computing Engagement}

We next examined student responses to TFS items that asked about engagement with and perceptions of computing (see Table 4). We found students who took both AP CS courses were significantly more likely to have reported writing computer code "frequently" in the last year (64.6\%), than those who took only CSA (53.3\%) or CSP (39.8\%). We also explored students' selfrated computer programming skills and found similar patterns, with significantly more students who took both AP CS courses (69.3\%) indicating their programming skills were "Above average or Highest $10 \%$ " among their peers, compared to students in the other two categories (57.4\% among those taking CSA and $38.5 \%$ among those taking CSP). It is notable that far fewer students who took only CSA reported coding most frequently and that 
those in this group were not as highly confident in their programming skills. Finally, we were also interested in students' perceptions of the broader applications of computer programming and examined the extent to which students believed that "a basic understanding of computer programming is important for nearly any career today." While at least onethird of students in each category indicated that they "strongly agree" with this statement, this sentiment was strongest among students who took both AP CS courses (39.2\%).

Table 4. Computing Engagement: Differences Across AP Course Takers (2017)

\begin{tabular}{|c|c|c|c|}
\hline & \multicolumn{3}{|c|}{ Percent Among } \\
\hline & $\begin{array}{l}\text { APCSA } \\
\quad(A) \\
n=5,948\end{array}$ & $\begin{array}{l}\text { APCSP } \\
\quad(P) \\
n=1,805 \\
\end{array}$ & $\begin{array}{c}\text { Both } \\
(\mathrm{B}) \\
\mathrm{n}=869 \\
\end{array}$ \\
\hline $\begin{array}{l}\text { Written computer code in the last } \\
\text { year ("Frequently") }\end{array}$ & $53.3^{\mathrm{PB}}$ & $39.8 \mathrm{AB}$ & $64.6^{\mathrm{AP}}$ \\
\hline $\begin{array}{l}\text { Self-rated computer programming } \\
\text { skills ("Above average;" Highest } \\
10 \% ")\end{array}$ & $57.4^{\mathrm{PB}}$ & $38.5 \mathrm{AB}$ & $69.3 \mathrm{AB}$ \\
\hline $\begin{array}{l}\text { At least a basic understanding of } \\
\text { computer programming is } \\
\text { important for nearly any career } \\
\text { today ("Strongly agree") }\end{array}$ & $32.3^{\mathrm{B}}$ & $34.0^{\mathrm{B}}$ & $39.2 \mathrm{AP}$ \\
\hline
\end{tabular}

\subsection{Major Aspirations}

To address the third research question, we explored the major and career interests of AP CS course-takers upon arriving to college. Results for students' self-reported college major are shown in Table 5. Students could select from among 90 different intended major categories, which were aggregated into the 17 broader categories shown in the table. Given our interest in the role of AP CS courses in broadening participation in computing in college and beyond, we first explored the extent to which students who took these courses were interested in pursuing a computing major (this aggregated category included "computer science", "computer/management information systems", and "other math/computer science"). We found that a substantial proportion of students who took both AP CS courses indicated intending to major in computing (38.1\%), compared to $28.3 \%$ of those who took only CSA and $16.9 \%$ among those who took only CSP.

We also looked at the other STEM majors in which AP CS course takers were interested. Notably, more than one-fifth of all AP CS course-takers intended to major in engineering, however this was significantly more likely among students who took only CSA $(26.9 \%)$ relative to those who took only CSP (22\%) or both courses $(21.9 \%)$. While students who took only CSP were less likely than students in the other groups to be interested in computing or engineering majors, they were significantly more likely to plan to major in the biological sciences (14\%) than the CSA group (10.8\%) or those who had taken both CS courses
(7.2\%). Beyond STEM, business was another popular major choice among students in our sample, however those who took only CSP $(10.3 \%)$ were more likely to indicate a business major than students who took only CSA $(7.2 \%)$ or both courses $(7 \%)$. Finally, given that our sample consisted of first-time college students, we also looked at the proportions of students in each group who were undecided about their major. Interestingly, 7.8\% of students who took only CSP had not yet decided on a major, significantly larger than the proportion among those who took only CSA (5.3\%) or both AP computing courses (3.4\%).

Table 5. Student Major Selections: Differences Across AP Course Takers (2017)

\begin{tabular}{|c|c|c|c|}
\hline & \multicolumn{3}{|c|}{ Percent Among } \\
\hline & $\begin{array}{c}\text { APCSA } \\
\text { (A) } \\
n=6,017\end{array}$ & $\begin{array}{c}\text { APCSP } \\
(\mathrm{P}) \\
\mathrm{n}=1,819\end{array}$ & $\begin{array}{c}\text { Both } \\
(B) \\
n=881\end{array}$ \\
\hline Agriculture & - & 0.2 & - \\
\hline Arts \& Humanities & $1.2^{\mathrm{P}}$ & $2.5 \mathrm{~A}$ & 1.8 \\
\hline Bio \& Life Sciences & $10.8^{\mathrm{PB}}$ & $14.0 \mathrm{AB}$ & $7.2^{\mathrm{AP}}$ \\
\hline Business & $7.2^{\mathrm{P}}$ & $10.3 \mathrm{AB}$ & $7.0^{\mathrm{P}}$ \\
\hline Computing & 28.3 РВ & $16.9 \mathrm{AB}$ & $38.1 \mathrm{AP}$ \\
\hline Education & 0.7 & 1.3 & 0.9 \\
\hline Engineering & $26.9^{\mathrm{PB}}$ & $22.0^{\mathrm{A}}$ & $21.9^{\mathrm{A}}$ \\
\hline English & 0.7 & 0.7 & 0.7 \\
\hline Fine Arts & $1.7^{\mathrm{B}}$ & 2.5 & $3.1^{\mathrm{A}}$ \\
\hline Health Professions & $2.1^{\mathrm{PB}}$ & $5.4^{\mathrm{A}}$ & $4.2^{\mathrm{A}}$ \\
\hline History/Political Science & 2.3 & 2.5 & 1.7 \\
\hline Justice \& Security & 0.4 & 0.9 & 0.5 \\
\hline Math/Statistics & 2.9 & 2.8 & 1.6 \\
\hline Physical Science & 3.9 & 3.2 & 3.1 \\
\hline Social Science & 4.5 & 5.6 & 3.7 \\
\hline Other Non-technical & 1.2 & 1.5 & 1.1 \\
\hline Undecided & $5.3^{\mathrm{P}}$ & $7.8 \mathrm{AP}$ & $3.4^{\mathrm{P}}$ \\
\hline
\end{tabular}

\subsection{Career Aspirations}

The career aspirations of students who took AP computing courses are shown in Table 6. On the TFS, students could choose from 64 probable careers, which were then aggregated into the broader categories we report. We were especially interested in the extent to which students who took these AP CS courses were interested in working in the careers under the information technology (IT) professional category, which aggregated three career options from the survey: "computer programmer/developer", "computer/systems analyst", and "web designer". Notably, more than one-third of the students $(31.8 \%)$ who took both AP CS courses indicated a probable career as an IT professional, a significantly higher proportion than students who took only CSA (23.2\%) and more than twice as high as the students who took only CSP (14.6\%). Beyond computing careers, we found that students who took only CSA were more interested than students in the other two groups in science careers in engineering, medicine, and scientific research. Those who took only CSP were interested in health careers as well as careers in business, and they were also significantly more likely than students in either of the other two groups to be undecided about their future careers. 
Table 6. Probable Career: Differences Across AP Course Takers (2017)

\begin{tabular}{|c|c|c|c|}
\hline & \multicolumn{3}{|c|}{ Percent Among } \\
\hline & $\begin{array}{l}\text { APCSA } \\
\text { (A) } \\
n=5,874\end{array}$ & $\begin{array}{l}\text { APCSP } \\
(P) \\
n=1,771\end{array}$ & $\begin{array}{c}\text { Both } \\
\text { (B) } \\
n=859\end{array}$ \\
\hline Agriculture/Natural Resources & 0.4 & 0.5 & 0.5 \\
\hline Artist & 2.7 & 3.7 & 3.4 \\
\hline Business & 11.1 & 12.6 & 10.2 \\
\hline Business (Admin Asst/ Clerical) & 0.2 & 0.2 & - \\
\hline Clergy & 0.1 & 0.1 & 0.3 \\
\hline College Faculty & 0.6 & 0.4 & 0.5 \\
\hline Communications & 0.6 & 0.7 & 0.9 \\
\hline Doctor (MD or DDS) & 10.7 & 11.5 & 8.5 \\
\hline Education (Elem/Sec) & $1.2^{\mathrm{P}}$ & $2.7^{\mathrm{A}}$ & 1.6 \\
\hline Engineer & $19.9^{\mathrm{P}}$ & $15.4^{\mathrm{A}}$ & 16.6 \\
\hline Government & 1.5 & 2.3 & 1.7 \\
\hline Health Professional & $2.3^{\mathrm{P}}$ & $3.8^{\mathrm{A}}$ & 3.0 \\
\hline $\begin{array}{l}\text { Homemaker/Stay-at-Home } \\
\text { Parent }\end{array}$ & 0.2 & 0.2 & 0.5 \\
\hline IT Professional \pm & $23.2^{\mathrm{PB}}$ & $14.6 \mathrm{AB}$ & $31.8 \mathrm{AP}$ \\
\hline Lawyer & 2.7 & 2.6 & 2.2 \\
\hline Military & 1.9 & 1.9 & 0.9 \\
\hline Nurse & $0.5^{\mathrm{PB}}$ & $1.6^{\mathrm{A}}$ & $1.3 \mathrm{~A}$ \\
\hline Research Scientist & $5.8^{\mathrm{B}}$ & $5.6^{\mathrm{B}}$ & $2.6 \mathrm{AP}$ \\
\hline Service Industry & 0.1 & 0.3 & 0.5 \\
\hline Skilled Worker & $0.1^{\mathrm{P}}$ & $0.6^{\mathrm{A}}$ & 0.1 \\
\hline Social/Non-Profit Services & $0.2^{\mathrm{P}}$ & $0.7 \mathrm{~A}$ & 0.1 \\
\hline Other & $5.0^{\mathrm{P}}$ & $6.5^{\mathrm{A}}$ & 6.5 \\
\hline Undecided & $9.3^{\mathrm{PB}}$ & $11.7 \mathrm{AB}$ & $6.2 \mathrm{AP}$ \\
\hline $\begin{array}{l}\text { Notes. Superscripts indicate significant } \\
\mathrm{A}=\text { Students who took APCSA; P=Stude } \\
\text { both CSA and CSP }\end{array}$ & $\begin{array}{l}\text { ifferences bet } \\
\text { ts who took A }\end{array}$ & $\begin{array}{l}\text { en groups a } \\
\text { SP; } B=\text { Stud }\end{array}$ & $\begin{array}{l}.01 . \\
\text { s who tool }\end{array}$ \\
\hline
\end{tabular}

\section{Discussion and Conclusion}

The recent introduction of APCSP to the College Board's AP offerings was motivated by the goal of increasing engagement in computing for a broader and more diverse range of students [6]. Building on prior comparisons of students who have taken these two courses or exams $[7,10]$, this study used nationwide data on college students entering their first year, and set out to understand the characteristics of those who had enrolled in CSP in high school and how they compared with students enrolled in CSA, as well as the unique subgroup of students who had enrolled in both courses.

Our findings suggest that CSP has indeed helped to diversify the population of students who take AP CS, as those who took only CSP included a larger proportion of those who identify as females, historically under-represented minorities, lowerincome, and first-generation college students. In contrast, students who reported only having taken CSA aligned more with demographics of those who have been historically wellrepresented in computing: male, White, and Asian. These findings reflect similar patterns found in analyses of AP CS exam takers [10]. Further, students who took both courses (presumably resulting from a combination of self-selection and opportunity to do so) exhibited traits that portend longer-term engagement and success in computing: more experience with coding, high confidence in programming, as well as interest in computing majors and tech careers.

These results raise questions about whether broadening participation in CSP translates to a more diverse pipeline of students in computing fields. One could argue that CSP has achieved its goal of expanding and diversifying the pool of high school students getting college-level education in computing principles and applications. It is possible that a good number of students taking this course simply would not have taken any computing course in high school if CSP were not offered. Further, given a recent College Board report stating that students taking CSP are substantially more likely than other AP STEM students (and students in general) to subsequently take CSA [5], one might view CSP as a critical gateway course to more advanced computing curricula. More research into the impact of the two courses together on the pipeline of students entering computing majors and professions is warranted.

However, our findings also indicate that students historically underrepresented in computing are disproportionately enrolled in a course that is less likely to prepare them for college-level computing majors, as other researchers have found that the two courses are differentially accepted for college credit and as prerequisites for college-level computing courses [9]. This raises important questions about what happens when students do not have the opportunity to also take CSA, particularly since those in our sample who took only CSP reported less experience with actual coding and much less interest in pursuing computing majors or technology careers.

Thus, despite the promise of CSP enabling a more diverse pipeline into computing, more research is needed to better understand the role that this course is playing to broaden participation in computing in college and beyond. First, research ought to address whether the diversity witnessed in CSP ultimately translates to greater (or even lesser) diversity in $\mathrm{CSA},{ }^{2}$ as well as which schools actually provide students with the opportunity to take both courses. Finally, to what extent does taking one or both APCS courses predict students' interest in computing majors and careers? Such investigations will be increasingly possible as both CSA and CSP continue to grow and students taking these courses matriculate into colleges and decide on career paths.

\section{ACKNOWLEDGEMENTS}

This study was supported by Pivotal Ventures. The authors also wish to thank the Cooperative Institutional Research Program at UCLA's Higher Education Research Institute for providing The Freshman Survey data used in this study.

\footnotetext{
${ }^{2}$ We conducted additional analyses using TFS data from 2016 and 2017 to see how the demographic characteristics of CSA students changed once CSP was fully introduced. We found few significant demographic differences between these two cohorts, suggesting that the introduction of CSP did not markedly change the composition of CSA enrollees.
} 


\section{REFERENCES}

[1] College Board. 2008. AP national report 2008. College Board: New York, NY. Retrieved from

https://research.collegeboard.org/programs/ap/data/archived/2008

[2] College Board. 2014. AP Computer Science A course description. Retrieved from https://apcentral.collegeboard.org/pdf/ap-computer-science-a-courseand-exam-description.pdf?course $=$ ap-computer-science-a

[3] College Board. 2017. AP Computer Science C course description. Retrieved from https://apcentral.collegeboard.org/courses/ap-computer-scienceprinciples/course

[4] College Board. 2017. AP national report 2017. College Board: New York, NY. Retrieved from

https://research.collegeboard.org/programs/ap/data/archived/ap-2017

[5] College Board. 2018. AP national report 2018. College Board: New York, NY. Retrieved from

https://research.collegeboard.org/programs/ap/data/participation/ap-2018

[6] Jan Cuny. 2015. Transforming K-12 computing education: AP computer science principles. ACM Inroads 6, 1 (March 2015), 58-59.

[7] Jonathon A. Good. 2018. Gender-related effects of Advanced Placement Computer Science courses on self-efficacy, belongingness, and persistence. $\mathrm{Ph} . \mathrm{D}$ Dissertation. Michigan State University, East Lansing, MI. ProQuest Number: 10845682.

[8] Joanna Goode, Julie Flapan, and Jane Margolis. 2018. Computer science for all: A school reform framework for broadening participation in computer science. In Tierney, W, Corwin, Z., \& Ochsner, A. (Eds.). Diversifying digital learning:
Online literacy and educational opportunity. Johns Hopkins Press, Baltimore, $\mathrm{MD}, 45-65$.

[9] Douglas Havard and Keith Howard. 2019. All Advanced Placement (AP) Computer Science is Not Created Equal: A Comparison of AP Computer Science A and Computer Science Principles. Journal of Computer Science Integration 2, 1 (Feb. 2019), 16-34. https://doi.org/10.26716/jcsi.2019.02.1.2

[10] Keith Howard and Douglas Havard. 2019. Advanced Placement (AP)

Computer Science Principles: Searching for equity in a two-tiered solution to underrepresentation. Journal of Computer Science Integration 2, 1 (Feb. 2019), 1-15. https://doi.org/10.26716/jcsi.2019.02.1.1

[11] Anya Kamenetz. 2017. Tens of thousands of minorities are taking computer science. Retrieved from https://www.npr.org/sections/ed/2017/07/31/539853090/tens-of-thousandsmore-women-and-minorities-are-taking-computer-science

[12] Jane Margolis, Jennifer J. Holme, Rachel Estrella, Joanna Goode, and Kim Nao 2017. Stuck in the shallow end: Education, race, and computing, revised edition. MIT Press: Boston, MA.

[13] National Center for Education Statistics. 2019. Public school locator. U.S. Dept of Education: Washington, DC. Retrieved from https://nces.ed.gov/ccd/schoolsearch/.

[14] National Center for Education Statistics. 2019. Private school universe survey. U.S. Dept. of Education: Washington, DC. Retrieved from https://nces.ed.gov/surveys/pss/privateschoolsearch/.

[15] Ellen B. Stolzenberg, M. Kevin Eagan, Melissa C. Aragon, Natacha M CesarDavis, Sidronio Jacobo, Victoria Couch, and Cecelia Rios-Aguilar. (2019). The American freshman: National norms fall 2017. Higher Education Research Institute at UCLA: Los Angeles, CA. 